RAD Conference Proceedings, vol. 4, pp. 18-22, 2020

ISSN 2466-4626 (online) | DOI: 10.21175/RadProc.2020.04

www.rad-proceedings.org

\title{
DOSE LOAD TO THE INTERVENTIONAL CARDIOLOGIST FOR DIFFERENT POSITIONS OF THE PATIENT TABLE - FIRST RESULTS
}

\author{
Natasha Ivanova ${ }^{1^{*}}$, Javor Ivanov ${ }^{2}$, Bistra Manusheva3, \\ Ismet Tahsinov4, Hrisimir Todorov4, Nikolai Aleksandrov4 \\ ${ }^{1}$ Medical University “Prof. Dr. Paraskev Stoyanov”, Varna, Bulgaria \\ ${ }^{2}$ S\&T Bulgaria EOOD, Sofia, Bulgaria \\ ${ }^{3}$ Head of Radiation Protection Department, Regional Health Inspectorate, Varna, Bulgaria \\ 4Invasive Department, Cardiology Hospital, Varna, Bulgaria
}

\begin{abstract}
In this article we present the first results of a study of the dose load received by a medical team working with an angiographic X-ray system in the Department of Invasive Cardiology. In the first stage, we made measurements of the equivalent dose received by an interventional cardiologist for the most commonly used projections of the C-arm, because we do not take into account the impact of the relevant tissue in the body that is irradiated. The measurements were made at three points of the cardiologist's body: head, gonads and feet. The purpose of this first step is to determine at which position of the patient table the operating cardiologist receives the lowest dose load for the most commonly used C-arm projections. From the obtained results it is reasonable to conclude that the factory set zero position of the patient table gives the lowest dose load for most of the projections used.
\end{abstract}

Keywords: G-arm type angiographic X-ray system, dose load, interventional cardiology, Cardiology Hospital

\section{INTRODUCTION}

Each angiographic procedure requires in-depth preparation, careful planning and use of the angiograph's positions to obtain the best possible projection. The exact choice of the appropriate projections gives maximum information and large free space for action of the cardiologist during the procedure. [1]

In addition to the medical aspect of the respective cardiomedical problem, the cardiologist also encounters technical challenges. He must be well acquainted with the properties of the angiographic equipment and make use of the resulting opportunities. Despite their widespread use, X-rays remain a harmful tool and the medical community and industry continue to look for ways to reduce their harmful effects on human health.

The history of the creation of X-ray machines by Phillips confirms this to a special extent. [2] Each stage of the creation of new equipment requires the knowledge and skills of many people who have forever connected their lives with the history of the creation of $\mathrm{X}$-ray equipment. [3]

The Philips Allura Xper FD10 X-ray angiographic system is a typical representative of modern equipment of this type. It provides intelligent and intuitive integration of multimodal images, patient information and specific applications in an interventional or hybrid surgical package. The system provides critical information needed by cardiologists to optimize the intervention procedures and to determine the optimal treatment. [4] The main projections used by the medical team of the Cardiac Hospital where we did our study are following:

Table 1. Projections for which the measurement was made

\begin{tabular}{|l|l|}
\hline LAO (Left Anterior Oblique) $90^{\circ}$ & $90^{\circ}$ \\
\hline LAO (Left Anterior Oblique) $30^{\circ}$ & $30^{\circ}$ \\
\hline PA (Posterior -Antero) & $0^{\circ} / 0^{\circ}$ \\
\hline RAO - cranial (Right Anterior Oblique - cranial) & $30^{\circ} / 30^{\circ}$ \\
\hline RAO - caudal (Right Anterior Oblique - caudal) & $30^{\circ} / 15^{\circ}$ \\
\hline LAO - cranial (Left Anterior Oblique - cranial) & $30^{\circ} / 30^{\circ}$ \\
\hline LAO - caudal (Left Anterior Oblique - caudal) & $30^{\circ} / 30^{\circ}$ \\
\hline Cranial & $30^{\circ}$ \\
\hline Caudal & $30^{\circ}$ \\
\hline
\end{tabular}

\section{METHODS}

\subsection{Dosimetric measurement}

We performed a dosimetric measurement of the dose received by a cardiologist performing an angiographic procedure. Measurements were performed for all of the 9 most commonly used C-arm projections. Each measurement was made at three points on the cardiologist's body: head, gonads and feet

*natasha_i@abv.bg 
and for three different table positions: zero height (according to the default system adjustment), lowest possible position for the respective projection and highest possible position for the respective projection.

\section{Practical MEASUREMENTS}

The practical measurements were made in the Specialized Hospital for Active Treatment in Cardiology (SBALK) Varna, in the Department of Invasive Cardiology.

\subsection{Participants}

Participants in the dosimetric measurements:

- the first author of this article - a representative of the Medical University and processing the received data,

- service engineer maintaining the X-ray equipment: the measurements were carried out under the direct and continuous control of the service engineer of the X-ray system,

- medical physicist - Head of the Radiation Protection Department at the Regional Health Inspectorate, Varna, working with the measuring device;

- three interventional cardiologists from the Cardiac Hospital who provided information and instructions on the interventional procedures and projections used during the measurements.

\subsection{Devices and materials}

The study was performed in a procedure room of an angiographic X-ray system with $\mathrm{C}$-arm Philips Allura Xper FD10 (Fig. 1).

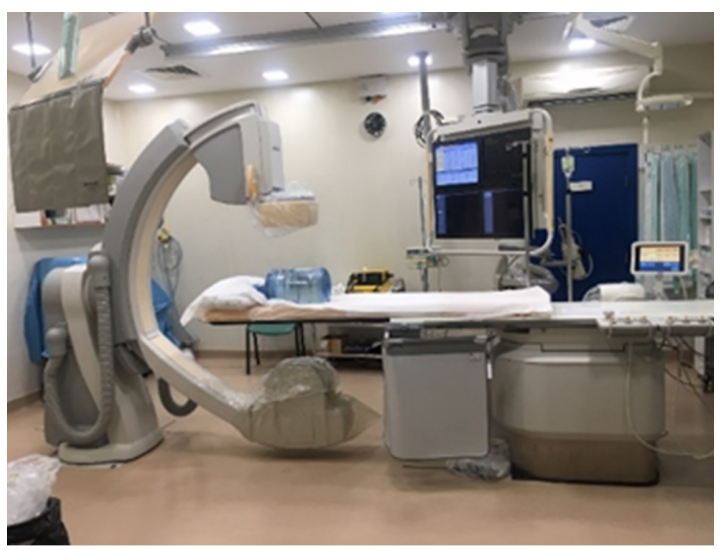

Figure 1. Angiographic X-ray system Philips Allura Xper FD10

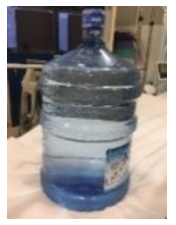

Figure 2. Phantom - a bottle of water with a volume of 19 liters.

A 19-liter water bottle was used as phantom (Fig.2.).
The dosimetric measurement was performed with X-Ray-Gamma-Dosimeter RGD 27091 (Fig.3.) [5].
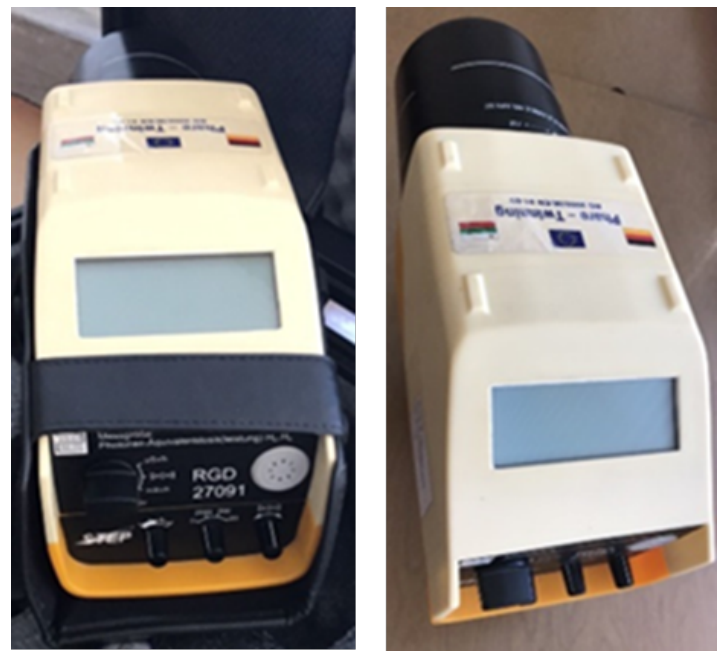

Figure 3. X-Ray-Gamma-Dosimeter RGD 27091 [5]

\subsection{Procedure}

An operator who worked with the X-ray equipment and a medical physicist performing the measurements, all protected with a personal protective equipment, took part in the measurements in the interventional room.

The operating mode of the equipment used was pulse fluoroscopy with parameters: $\mathrm{U}=120 \mathrm{kV}$; $\mathrm{I}=6 \mathrm{~mA}$; $\mathrm{t}=2 \mathrm{~s}$. During the measurement, only the position of the patient table changed: zero, lowest and highest position for each of the measured projections. The position of the operator in relation to the equipment and the patient table with the measured points and its distance from the radiation shield of the angiograph is shown in Fig.4.

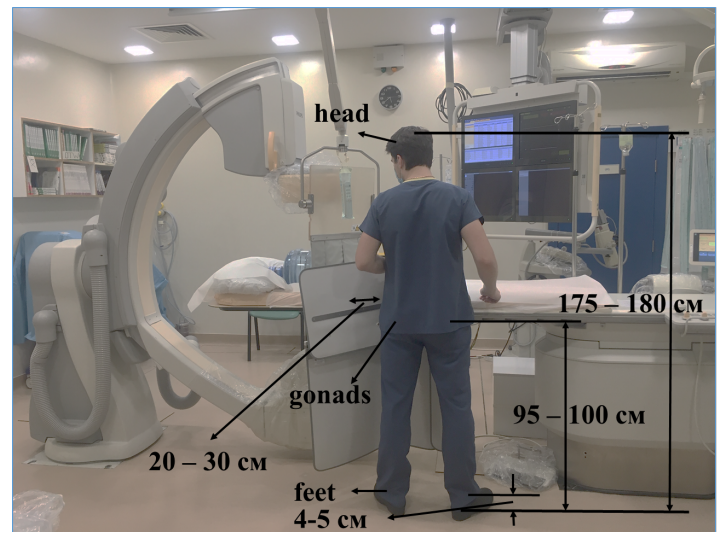

Figure 4. Position of cardiologist in relation to patient table, $\mathrm{C}$-arm, radiation protection shield. Measuring points: head, gonads and steps

\section{RESUlts}

The measurements were repeated 3 to 5 times. Table 2 shows the average values from the 
measurements, rounded to the nearest hundredth. In Table 2 and the diagrams $(1,2,3,4)$ are presented the significant figures of the value obtained for each measurement, multiplied by $10^{-2}$.

Table 2. Dose received by the cardiologist, measured at three points on his body, for three different positions of the patient's table

MEASURING POINTS:

\begin{tabular}{|c|c|c|c|c|}
\hline \multicolumn{2}{|c|}{ PROJECTIONS patient table position } & \multicolumn{3}{|c|}{$\begin{array}{l}\mathbf{y . 1 0 ^ { - 2 }} \\
\mu \mathrm{Sv}\end{array}$} \\
\hline \multirow{3}{*}{ LAO $3^{\circ}$} & lowest, $x=-9 \mathrm{~cm}$ & 1 & 3 & 2 \\
\hline & highest, $x=+13 \mathrm{~cm}$ & $\mathbf{1}$ & 5 & 3 \\
\hline & zero, $x=o \mathrm{~cm}$ & 1 & 3 & 3 \\
\hline \multirow{3}{*}{ LAO 90 } & lowest, $x=-13 \mathrm{~cm}$ & $\mathbf{1}$ & 2 & 4 \\
\hline & highest, $x=+13 \mathrm{~cm}$ & $\mathbf{1}$ & 4 & 2 \\
\hline & zero, $x=o \mathrm{~cm}$ & $\mathbf{1}$ & 3 & 3 \\
\hline \multirow[t]{3}{*}{ PA o $^{\circ} / \mathbf{o}^{\circ}$} & lowest, $x=-13 \mathrm{~cm}$ & $\mathbf{1}$ & $\mathbf{1}$ & $\mathbf{1}$ \\
\hline & highest, $x=+13 \mathrm{~cm}$ & $\mathbf{1}$ & 2 & 3 \\
\hline & zero, $x=0 \mathrm{~cm}$ & $\mathbf{1}$ & 2 & 3 \\
\hline \multirow{3}{*}{$\begin{array}{l}\text { RAO - cranial- } \\
\mathbf{3 0}^{\circ} / \mathbf{3 0}^{\circ}\end{array}$} & lowest, $x=-8 \mathrm{~cm}$ & $\mathbf{1}$ & 3 & 3 \\
\hline & highest, $x=+13 \mathrm{~cm}$ & 5 & 4 & 5 \\
\hline & zero, $x=0 \mathrm{~cm}$ & 2 & 4 & 4 \\
\hline \multirow{3}{*}{$\begin{array}{l}\text { RAO - caudal- } \\
3^{\circ} / 15^{\circ}\end{array}$} & lowest, $x=-9 \mathrm{~cm}$ & $\mathbf{1}$ & 4 & 6 \\
\hline & highest, $x=+13 \mathrm{~cm}$ & 2 & 5 & 5 \\
\hline & zero, $x=0 \mathrm{~cm}$ & 1 & 3 & 5 \\
\hline \multirow{3}{*}{$\begin{array}{l}\text { LAO - } \\
\mathbf{3 0}^{\circ} / \mathbf{3 0}^{\circ}\end{array}$} & lowest, $x=-3 \mathrm{~cm}$ & 2 & 5 & 2 \\
\hline & highest, $x=+$ & $\mathbf{1}$ & 5 & 3 \\
\hline & zero, $x=o \mathrm{~cm}$ & $\mathbf{1}$ & 5 & 2 \\
\hline \multirow{3}{*}{$\begin{array}{l}\text { LAO - caudal- } \\
3^{\circ} / 3^{\circ}\end{array}$} & lowest, $x=-2 \mathrm{~cm}$ & $\mathbf{1}$ & 3 & 4 \\
\hline & highest, $x=+$ & 1 & 5 & 3 \\
\hline & zero, $x=0 \mathrm{~cm}$ & $\mathbf{1}$ & 4 & 5 \\
\hline \multirow[t]{3}{*}{ Cranial- $\mathbf{3 0}^{\circ}$} & lowest, $x=-9 \mathrm{~cm}$ & 1 & 3 & 3 \\
\hline & highest, $x=+$ & $\mathbf{1}$ & 5 & 5 \\
\hline & zero, $x=0 \mathrm{~cm}$ & 1 & 4 & 3 \\
\hline \multirow[t]{3}{*}{ Caudal-3o ${ }^{\circ}$} & lowest, $x=-13 \mathrm{~cm}$ & 4 & 8 & 4 \\
\hline & highest, $x=+$ & 2 & 4 & 3 \\
\hline & zero, $x=0 \mathrm{~cm}$ & 2 & 4 & 2 \\
\hline
\end{tabular}

Table 3. Standard deviations for three position of the patient table

\begin{tabular}{|c|c|c|c|}
\hline & head & gonads & feet \\
\hline lowest & 0.342 & 0.672 & 0.500 \\
\hline highest & 0.443 & 0.333 & 0.425 \\
\hline zero & 0.147 & 0.294 & 0.373 \\
\hline
\end{tabular}

Table 3 gives the values of the standard deviations for the three patient table positions at the three measured points. The minimum value of the standard deviation is 0.147 at zero table position at the measured point "head", and the maximum 0.672 - at the lowest table position at the measured point "gonads".

Diagram 1 shows the comparison of the data obtained from all measurements made for the different positions of the patient table, for the different projections of the angiographic system. It shows the variety in the dose values. A single maximum value of $8.10^{-2} \mu \mathrm{Sv}$ is observed, only in the measurement point "Gonads", for the lowest position of the patient table, in caudal projection. The second largest obtained value of $6.10^{-2} \mu \mathrm{Sv}$ is again in the lowest position of the table, but at the measurement point "Steps", in the RAO projection - caudal. Also in this projection, the X-ray tube radiates towards the operator's body. Almost all projections, except for the PA projection, have one or more measured values of $5.10^{-2} \mu \mathrm{Sv}$. Most of these are at the point "Gonads" - 7 measurements, and the lowest value here is measured only at the point "Head", in the projection RAO - cranial, for the highest position of the patient table.

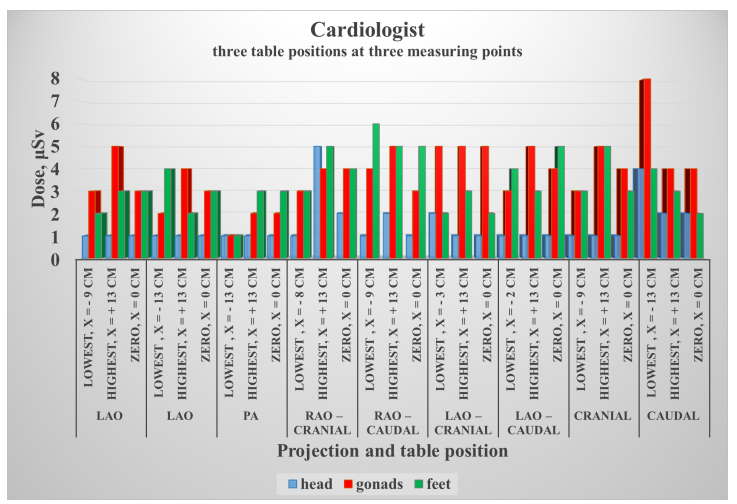

Diagram 1. Dose received by the cardiologist, measured at three points on his body, for three different positions of the patient's table

In the predominant number of measurements the value of $1.10^{-2} \mu \mathrm{Sv}$ was observed - for all projections and most often in the point "Head" (20 measurements).

For the lowest position of the patient table, the most varied values in the measurements were obtained.

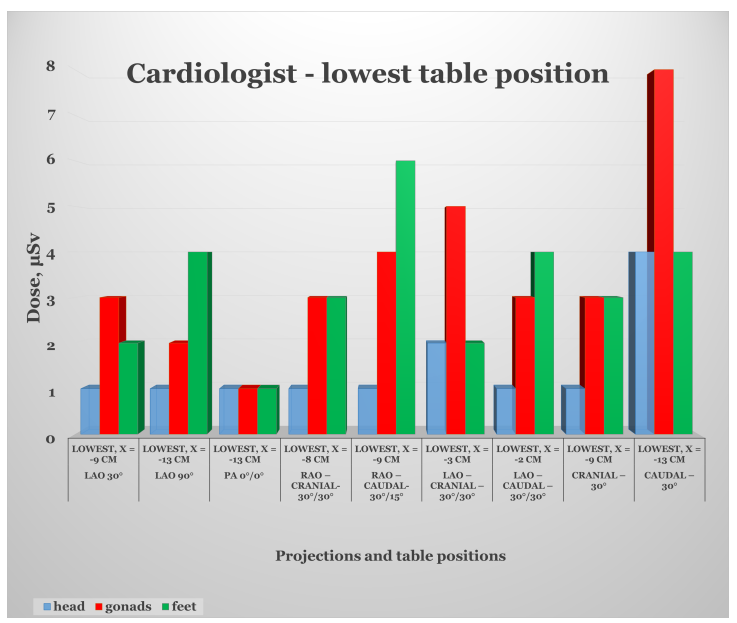

Diagram 2. Dose received by the cardiologist, measured for the lowest position of the patient table at all the three measurement points. 
N. Ivanova et al., Dose load for different positions of the patient table, RAD Conf. Proc., vol. 4, 2020, 18-22

The peak values were measured as follows - one of $8.10^{-2} \mu \mathrm{Sv}$, a lower value of $6.10^{-2} \mu \mathrm{Sv}$ and one of $5.10^{-2}$ $\mu \mathrm{Sv}$. Low values of $1.10^{-2} \mu \mathrm{Sv}$ were observed in 9 measurements. (Diagram. 2)

The highest position of the patient table shows relatively stable values for the various projections 9 measurements with maximum values of $5 \cdot 10^{-2} \mu \mathrm{Sv}$ and 6 measurements with minimum values of $1.10^{-2}$ $\mu$ Sv. The remaining 12 measurements show variable values: $2.10^{-2} \mu$ Sv to $4 \cdot 10^{-2} \mu \mathrm{Sv}$ (Diagram 3 ).

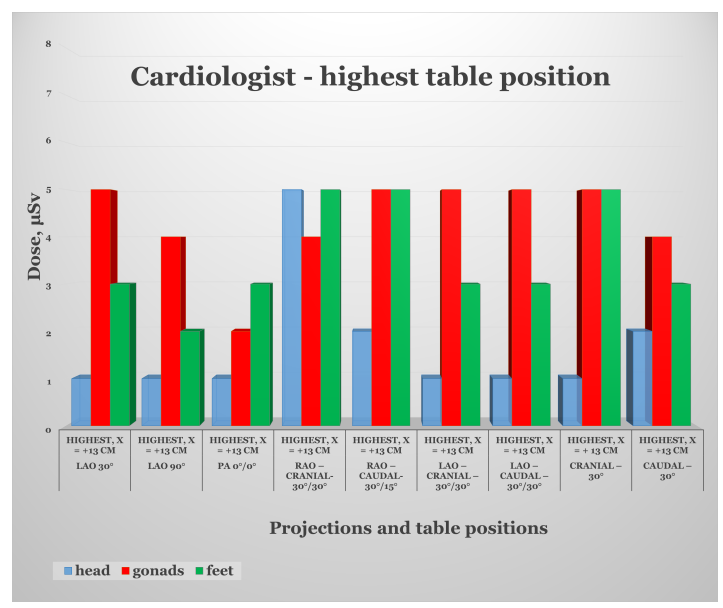

Diagram 3. Dose received by the cardiologist, measured for the highest position of the patient table at all the three measurement points

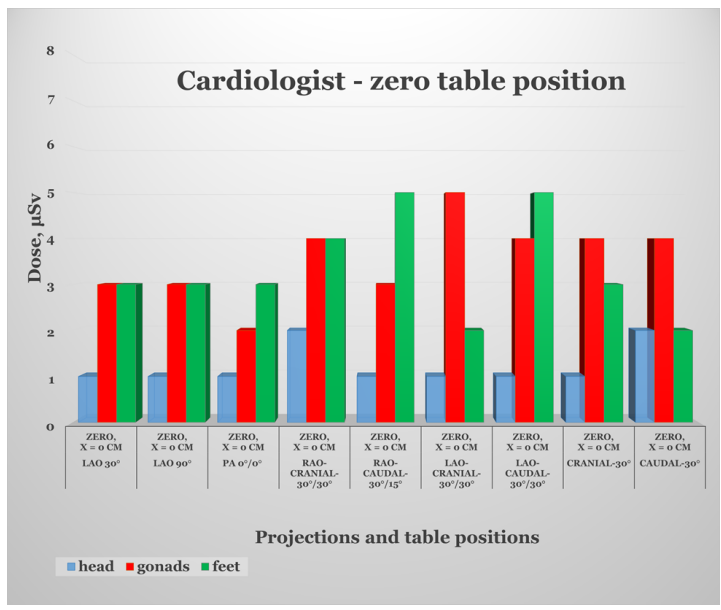

Diagram 4. Dose received by the cardiologist, measured for the zero position of the patient table at all the three measurement points

The zero position of the patient table shows lowest dose values of all measurements. Only three peak values were observed of $5.10^{-2} \mu \mathrm{Sv}$ for three different projections. All other values are between $1.10^{-2} \mu \mathrm{Sv}$ and $4.10^{-2} \mu \mathrm{Sv}$, where 12 of the measurements show low dose values between $1.10-2 \mu \mathrm{Sv}$ and $2.10^{-2} \mu \mathrm{Sv}$. (Diagram. 4.)

\section{CONCLUSION}

Table 4. Number of repetitions of the values, obtained for the three table positions

\begin{tabular}{|c|c|c|c|c|c|c|c|c|}
\hline \multirow{3}{*}{$\begin{array}{c}\text { Table } \\
\text { position }\end{array}$} & \multicolumn{8}{|c|}{ Values, $y \times 10^{-2} \mu S v$} \\
\hline & 1 & 2 & 3 & 4 & 5 & 6 & 7 & 8 \\
\hline & \multicolumn{8}{|c|}{ Number of repetitions of the values } \\
\hline Lowest & 9 & 4 & 6 & 5 & 1 & 1 & - & 1 \\
\hline Highest & 6 & 4 & 5 & 3 & 9 & - & - & - \\
\hline Zero & 7 & 5 & 7 & 5 & 3 & - & - & - \\
\hline
\end{tabular}

Analyzing these first results of our study we can do the following conclusions (Table 4):

In the zero position of the patient table, 8 peak values are observed - three values of 5.10-2 $\mu \mathrm{Sv}$ and five values of $4.10-2 \mu \mathrm{Sv}$. The values of $4.10-2 \mu \mathrm{Sv}$ predominate here.

In the highest position of the table, the values equal and higher than 4.10-2 $\mu \mathrm{Sv}$ are 12 in number, 9 of which are of 5.10-2 $\mu \mathrm{Sv}$ and three of 4.10-2 $\mu \mathrm{Sv}$. The values of 5.10-2 $\mu \mathrm{Sv}$ predominate here.

For the lowest table position, the values of 4.10-2 $\mu \mathrm{Sv}$ and higher are 8 in number -5 of them are 4.10-2 $\mu S v$ and 3 of them higher than 4.10-2 $\mu$ Sv. Here we see higher peak values - one is $8.10-2 \mu \mathrm{Sv}$, one is $6.10-2$ $\mu \mathrm{Sv}$ and one is $5.10-2 \mu \mathrm{Sv}$. Here, as in the zero position of the table, the $4.10-2 \mu \mathrm{Sv}$ values predominate, but the results above $4.10-2 \mu \mathrm{Sv}$ are more in number.

If a comparison is made of the higher values - 4.10$2 \mu \mathrm{Sv}$ and higher - it can be seen that the highest dose is obtained for the highest position of the patient table. The lowest dose load here is in the zero position.

Analyzing the obtained values of $3.10-2 \mu \mathrm{Sv}$ and lower, the following is observed:

In the zero position of the table, all measured values are 19 - seven values are 3.10-2 $\mu$ Sv, five are 2.10-2 $\mu \mathrm{Sv}$ and seven are 1.10-2 $\mu \mathrm{Sv}$. The number of the observed values of $1.10-2 \mu \mathrm{Sv}$ and $3.10-2 \mu \mathrm{Sv}$ is the same and they are predominant for this table position.

The number of the obtained values for the highest position of the patient table is 15 - five of them are 3.10-2 $\mu$ Sv, four are 2.10-2 $\mu \mathrm{Sv}$ and six are 1.10-2 $\mu$ Sv. The value of $1.10-2 \mu \mathrm{Sv}$ predominates, and the number of the 2.10-2 $\mu \mathrm{Sv}$ results is the lowest.

For the lowest position of the patient table, the total number of low values is 19 , similar to the zero position. Six of them are 3.10-2 $\mu \mathrm{Sv}$, four are 2.10-2 $\mu \mathrm{Sv}$ and nine are $1.10-2 \mu \mathrm{Sv}$. The value $1.10-2 \mu \mathrm{Sv}$ is predominant and $2.10-2 \mu \mathrm{Sv}$ is observed as frequently as in the case of the highest table position..

When comparing the values for the highest and lowest table position, it becomes clear that the total number of low values for the lowest table position is greater (19 compared to 15). In addition, the number of values of $1.10-2 \mu \mathrm{Sv}$ is higher for the lowest table position (9 compared to 5). The number of the results of 3.10-2 $\mu \mathrm{Sv}$ for the lowest position of the patient table is higher only by one (6 compared to 5 ). In this comparison between the lowest and the highest table position, it can be seen that the lowest position of the patient table, although with a small amount, gives a lower dose load. 
N. Ivanova et al., Dose load for different positions of the patient table, RAD Conf. Proc., vol. 4, 2020, 18-22

If one compares the low dose results for the zero position and the lowest position of the patient table, it can be seen that the number of the $1 \mu \mathrm{Sv}$ results is greater (9 compared to 7 ). The number of the 3.10-2 $\mu \mathrm{Sv}$ results is larger by one (6 compared to 7 ). It follows that if a comparison is made for the obtained low dose values (3.10-2 $\mu \mathrm{Sv}$ and lower), a lower dose load is observed for the lowest position of the patient table.

Dividing the obtained dose values into two groups of 4.10-2 $\mu \mathrm{Sv}$ and higher and of 3.10-2 $\mu \mathrm{Sv}$ and lower respectively and comparing them for the various table positions, different results for the dose load are obtained: for the higher values the zero position of the table is more favorable, and for the lower values the lower position of the table is more favorable. It is difficult to say which of the two positions gives a lower dose load. If we take into account the fact that for the group of higher values there are two peak values for the lowest position of the patient table, and for the group of lower values the difference of the number of equal values for each of the procedures is low, it can be concluded that the lowest dose load is obtained in the the zero position of the patient table.

In fact, no definite conclusion can be drawn from this analysis of the results. In order to clarify at which position the minimum dose load is received, it is necessary to make a more accurate analysis by comparing the values measured at different measurement points for different positions of the patient table.

From the analysis made so far there is one sure conclusion:

The highest position of the patient table gives the highest dose load according to our study.

Acknowledgements: We express our great gratitude to the Specialized Hospital for Active Treatment in Cardiology, Varna and especially to its director and the staff, for the permission to conduct our study and for the invaluable help and support they provided us.

We also express our gratitude to Philips, which supported us in our research, providing us with the necessary materials and photos used in the article.

\section{REFERENCES}

1. Von Schmilowski E., Swanton R. H., Essential Angioplasty 2012, Publisher:Wiley-Blackwell, ISBN 13:9781119950547

Retrieved from:

https://bk.lat $/$ book $/ 2151973 / 6 a 2 c b a ?$ regionChanged $=\&$ redi rect $=5046845$ Retrieved on: Sept. 21, 2020

2. PHILIPS, History of X-ray.

Retrieved from:

https://www.philips.com/consumerfiles/newscente r/main/shared/assets/Downloadablefile/FACT_SH EET X-ray history.pdf

Retrieved on: Sept. 21, 2020

3. J.A.M. Hofman, Former Marketing Director, Universal RF Systems, Philips Healthcare, The art of medical imaging: Philips and the evolution of medical X-ray technology, Clinical applications, MEDICAMUNDI 54/1 2010

4. Making the difference with Philips Live Image Guidance Philips Allura Xper FD10 system specifications (C) 2017 Koninklijke Philips N.V. 4522 $99118981 *$ Apr 2017 (The article was provided to me by Philips)

5. Röntgen-GammaDosimeter 27091, Technical Description and Operating Instructions, September 02, 2008

Retrieved from: http://www.step-

sensor.de/media/main/rgd 27091 manual .pd $\underline{f}$

Retrieved on: Sept. 21, 2020 